\title{
Maputo e o tempo das mangueiras em flor
}

\section{Luana Antunes Costa ${ }^{1}$}

2011. Era setembro e as mangueiras floriam nas ruas e nos quintais da cidade. Quando o avião da LAM, Linhas Aéreas Moçambicanas, fazia as manobras para o pouso, eu, da janela, observava: Maputo tinha a cor da terra. Enfim, Moçambique! Há tempos planejava uma viagem por este país, para além daquela proporcionada pela leitura de romances, contos e poemas. Pela literatura descortinava o país desde a leitura de Terra Sonâmbula, primeira obra que conheci da literatura moçambicana nos tempos da graduação em Letras. Depois da leitura deste romance, me aventurei por outras obras, fui conhecendo as gentes, a terra e as páginas de João Paulo Borges Coelho, Luis Bernardo Honwana, Paulina Chiziane, Eduardo White, Ruy Knopli, Noémia de Souza, José Craveirinha, Lília Momplé, Mia Couto... Alguns livros chegaram até mim pelas mãos de amigos africanos que, como eu, estudaram na Universidade Estadual Paulista, em Araraquara.

Há cerca de 10 anos, Moçambique, pela literatura, se tornara objeto de minhas pesquisas, uma segunda casa, um lugar que me trazia memórias de outras terras, como se sob suas cartografias poéticas e ficcionais, houvesse outras, ecos dos interiores do Brasil. Para além das obrigações oriundas do trabalho acadêmico e da necessidade de ir a campo quando se pesquisa a produção literária de um país africano, de fato, foram essas vozes para lá e para cá do Atlântico que me impulsionaram a querer ver, a desejar conhecer de perto as cores de Moçambique. E eu nem imaginava que a viagem que me levaria a tal país se desenharia em outro sul, às margens do rio da Prata, na charmosa Colonia del Sacramento, no Uruguay. Escrevo este texto e me lembro das tantas viagens e dos tantos encontros que a minha estada em Moçambique provocara e ainda provoca.

1 Doutoranda em Letras - Estudos Comparados de Literaturas de Língua Portuguesa, Universidade de São Paulo. Bolsista Capes. 
Como uma caixa de sândalo, outra viagem guardava a semente de minha visita a Moçambique e, felizmente, os sentidos estavam atentos e eu pude vislumbrá-la.

2010. Era novembro e as buganvílias coloriam os muros dos casarios. Há 2 dias estava em Colônia e enquanto visitava seus pontos turísticos me perguntava onde estava registrada a memória da colonização portuguesa naquele lugar, com as devidas honrarias aos negros traficados que construíram toda aquela cidade. Não encontrava nenhum monumento, nenhuma placa, nenhum muro, nem um breve texto informando à população de estrangeiros e locais da ocorrência do tráfico negreiro naquela parte da América do Sul, nem de como foram dizimados, nem das reminiscências de sua história. Havia sim, a história contatada sobre a construção do forte e das lutas travadas pelos portugueses contra os espanhóis e britânicos para manter sua possessão. Nada de novo em se tratando da versão colonial da conquista. E os turistas sacavam suas fotos. Será que dedicavam um pensamento à presença africana talhada na construção de Colônia, entranhada ao rococó dos casarios? Como não encontrava nenhuma placa ou registro público que mencionasse ali a presença dos negros africanos, resolvi buscar informações por conta própria (vício de uma pesquisadora negra em férias, talvez!). Entro em uma galeria de fotos e eis que me deparo com um brasileiro, fotógrafo, apaixonado por candomblé e pela resistência da ancestralidade africana nas artes uruguaias. Era ele o proprietário da loja e após uma aula sobre a História de Colônia de Sacramento e do candomblé, o sujeito me diz que, naquela altura só havia dois negros a circular pela pequena cidade, eu e um turista moçambicano. No dia seguinte, quando fui à galeria me despedir do meu conterrâneo, fui apresentada ao tal moçambicano e após alguns minutos de conversa, me surpreendo quando o gentil senhor me diz o seu sobrenome... Conheci Pedro Pimenta, realizador do Dockanema, Festival do filme documentário em Moçambique. Curiosamente, dias antes de chegar a Colônia, publiquei um texto num site brasileiro sobre o mesmo Festival.

Após esse encontro, seguimos em contato e quando, em São Paulo, me juntei aos amigos e companheiros de trabalho, o geógrafo Antonio Carlos Malachias, o antropólogo moçambicano Carlos Subhuana e o poeta Allan da Rosa para arquitetar um projeto de ações a ser desenvolvido em Maputo, logo Pedro Pimenta mostrou-se solidário e nos convidou a participar da $6^{\mathrm{a}}$ edição do Dockanema. A carta convite, assinada por Pedro, em nome do Festival, foi necessária para que solicitássemos o visto à Embaixada de Moçambique, localizada em Brasília. Embora tivessem participado da elaboração do projeto, Antonio Carlos Malachias e Carlos Subhuana não puderam 
seguir viagem por conta de outros compromissos firmados no Brasil, assim, os preparativos da viagem se seguiram orquestrados por Allan da Rosa e eu. As passagens foram adquiridas aqui no Brasil, por intermédio de uma agência de turismo, ainda que a agente que nos atendeu confessasse que não era muito comum em sua agência à procura pelo roteiro São Paulo, Maputo, São Paulo. Como ela não soube me dizer qual seria o melhor voo, optei pela empresa South African com conexão em Johannesburgo e prosseguimento da viagem, até Maputo, pela LAM. Munidos de nossos passaportes com visto de turista válido por 30 dias em terras moçambicanas, atestado internacional de vacina (necessário para entrar no país), seguimos viagem. Deixava São Paulo na tarde do dia 31 de agosto, sob um céu cinza e carregado de chuva, e após cerca de 12 horas de voo, o avião pousava no aeroporto de Johannesburgo.

No balcão da LAM, percebo que a atendente sul-africana não fala português. Também não fala espanhol ou francês... E eu me arrependo de não ter terminado nenhum dos cursos de inglês que comecei ao longo dos últimos 10 anos... Após algum tempo e algumas trocas sonoras entendemos o que se passava: overbooking! A moça, um tanto impaciente, ordena que eu e os outros passageiros nos sentemos e aguardemos. Ouço um "Sit!", um tanto brusco, e torço o nariz para a moça. Por fim, meu parceiro de trabalho, Allan da Rosa, consegue se comunicar com um atendente simpático no balcão da South African que nos pede agilidade para o embarque. Confesso que o corre-corre do aeroporto me deixou em estado de alerta e com ele ligado chegamos à capital de Moçambique.

Maputo tem o calor do Rio de Janeiro, mas diferente. No aeroporto, o calor me obriga a me desvencilhar da blusa e das meias. Dirigimo-nos para a esteira das malas e eis a surpresa: a minha, cheia de fitinhas rendadas e brancas, presentes de minha mãe, ali estava, porém a mala cheia de livros de Allan ficara em Johannesburgo, segundo um funcionário do aeroporto. Quando inquirido sobre o paradeiro da mala, o senhor respondera, com uma tranquilidade de causar inveja: “... Há de vir...” Lembro-me desta cena enquanto escrevo essas linhas e sorrio: a calma do sujeito enquanto enunciava esta expressão que tanto ouvi ao longo da viagem. Durante este mês de setembro descobri que o "há de vir" é uma expressão fora do nosso tempo, é quase para além do tempo e justifica todo e qualquer atraso, todo e qualquer imprevisto. Seria uma explicação para os desvios, provocados pelas ações humanas (ou não) no curso comum do tempo? "Uma hora chega, se pá..." Talvez o "há de vir" queira dizer isso no meu português cotidiano. Imagino. A mala chegaria a Maputo, intacta, dentro de poucos dias. 
Ainda no aeroporto troquei alguns dólares pelo dinheiro local, meticais. A face de Samora Machel, o primeiro presidente de Moçambique independente, estava ali estampada nas notas. Aos pouquinhos ia descobrindo a força da memória deste homem manifestada nas tantas histórias contadas e recontadas por moçambicanos e moçambicanas de diferentes gerações que eu encontrava pela cidade. Do Aeroporto Internacional de Maputo, apanhamos um táxi, e fomos para as casas dos amigos que nos hospedariam. Allan seguiu para a geografia do centro, região chamada de Baixa. Eu fui para o bairro Malhangalene, hoje, um dos meus lugares de afeto. Para além do alto fluxo do trânsito, o que mais me chamou a atenção nesta rota foi um outdoor. Ele estava posicionado estrategicamente logo após a saída do aeroporto, numa rotatória. Nele, um corpo feminino, com destaque para a região dos quadris, envolto numa roupa-rótulo, anunciava o slogan da cerveja: "Esta preta foi de boa para melhor - Agora com uma garrafa mais sexy". Como não lembrar das muitas e comuns propagandas brasileiras que aliam o produto cerveja ao corpo feminino? Lembrei-me, imediatamente, de quando chegava à rodoviária do Rio de Janeiro, em 2006, pronta a me instalar na cidade. Ao sair da rodoviária, estranhando o calor mole de praia e o barulho da cidade, deparei-me com vários cartazes anunciando a nova Devassa Preta. Senti-me mal com aquilo. A mesma sensação experimentava agora em Maputo.

Nos dias seguintes acompanhei conversas, discussões acaloradas, reações de diferentes tipos a tal propaganda sexista. A Liga Moçambicana dos Direitos Humanos e o Fórum Mulher foram às ruas, foram à imprensa e dias depois a propaganda foi retirada de circulação pela Empresa Cervejas de Moçambique ${ }^{2}$. E foi então que, a partir deste fato cotidiano e histórico, passei a observar e a estar mais próxima do feminino moçambicano: mulheres que negociavam no mercado; aquelas que vendiam legumes e frutas da estação sobre suas capulanas, ao chão ou em barracas; outras, estrangeiras em Maputo, vindas do norte do país, ou de outras nações africanas, como Suazilândia; as indianas com seus coloridos todos; as que não soube identificar de onde eram e que me cumprimentavam com o olhar, vestidas com suas burcas; outras, que me traziam lembranças de minhas amigas brasileiras, como a psicóloga Joana Borges, que pelos laços de amor se reinventava em fronteiras, entre o Brasil, Portugal e Moçambique. Aprendi também a tratar as mais velhas por Mamãs. Quando saía da casa de Joana e

2 "Mulheres consideram insultuosa publicidade a nova cerveja". Jornal Diário de Notícias Globo.

http://www.dn.pt/inicio/globo/interior.aspx?content_id=1980046\&seccao=CPLP 
Dover, para o trabalho no Centro Cultural Brasil Moçambique ${ }^{3}$, encontrava uma dessas senhoras que vendia legumes e frutas perto da Placeta do Malhangalene. Com ela, a quem eu chamava por Mamã, aprendi um outro tempo de se tecer cumprimentos, de olhar o outro ou de lhe estender a mão. Não era o tempo paulistano do cumprimento voraz, instantâneo, era uma dedicação a alguém, ali, diante de ti. Por vezes ela me perguntava de minha família, por minha mãe e meu pai e meus irmãos... E eu contava deles como se ela fosse uma amiga de minha família ou uma tia mais velha. Era assim que começava o meu dia em Maputo: uma conversa com alguma Mamã pela manhã, puxada por um simples bom dia, como estás?, depois, a caminhada do Malhangalene à Baixa, passando pelas avenidas Karl Marx e Samora Machel, quase uma reta, uma mesma direção. Neste percurso descobria uma vida inteira: um casamento, crianças indo e voltando da escola, um senhor indiano que vendia cabelos e produtos de beleza numa barraquinha (um dia, ele me confessou que os cabelos vinham do Brasil e que ele era assíduo frequentador do Brás onde comprava roupas e cabelos para revender em Maputo), mulheres e homens vendendo roupas e sapatos nas calçadas (as tais calamidades), um senhor que vendia flores na esquina da avenida Karl Marx com a Eduardo Mondlane, os motoristas das txopelas (um triciclo eficaz para a circulação na cidade, que funciona como um táxi), passageiros dos chapas (vans que funcionam como lotações), mais crianças... Costurando tudo isso havia também uma língua misturada ao português moçambicano, o changana, falado em Maputo e em outras partes do sul de Moçambique. Havia outras línguas também, certamente, dos moçambicanos de outras províncias, todos ali, no fuzuê da capital.

No Centro Cultural Brasil Moçambique, à época dirigido pelo professor e poeta Calane da Silva, com os jovens poetas e poetisas do Movimento Kuphaluxa, grupo que me recepcionou e que esteve comigo durante toda a viagem, encontramos espaço para desenvolver o projeto Brasilidades Africanas. O público, em sua maior parte jovem, compareceu às sessões de discussões e às palestras sobre educação para as relações étnico-raciais e literatura periférica brasileira, esteiras de atuação do poeta Allan da Rosa, no campo da educação popular em São Paulo e minhas também, como professora de literaturas africanas e afro-brasileira do núcleo ERER da Prefeitura de São Paulo. Com o Kuphaluxa aprendi que, mesmo com todas as dificuldades encontradas para a circulação e editoração de textos literários em Moçambique, as redes de trocas de

3 Cf. informações sobre o Centro Cultural Brasil Moçambique: http:/ / ccbmmaputo.blogspot.fr/ 
saberes e o ato solidário se fazem presentes na cidade e ganham força. Ações, como a organização de palestras nas escolas tendo por convidados escritores (as) e poetas (isas) moçambicanos (as), a publicação da revista on line Literatas, o projeto Poesia nas Acácias, e tantas outras iniciativas para a difusão e a popularização da literatura de países africanos e do Brasil, são tecidas por estes jovens, cotidianamente, como gesto de resistência e de esperança.

Voltei ao Brasil após um mês de trabalho e de vida em Moçambique. Depois de algum tempo, parti para redesenhar outra geografia, reescrever outras histórias. Este texto, tentativa de burilar o tempo e convite aberto a outros viajantes, foi escrito numa travessia, em Paris, quando o sol anuncia a primavera e pinta de verde as águas do Sena. No fim deste relato, descubro que a viagem, como diz Mia Couto, "não começa quando se percorrem distâncias, mas quando se atravessam nossas fronteiras interiores". Daqui, vejo e sinto que minha casa também é lá, à beira do Índico, onde as mangueiras anunciam futuros. 